\title{
Web Review: Webzines related to radiology and imaging
}

\author{
IK Indrajit \\ Department of Radiodiagnosis and Imaging Command Hospital (Air Force), Bangalore - 560 007, Karnataka, India
}

Correspondence: Dr. IK Indrajit, Department of Radiodiagnosis and Imaging Command Hospital (Air Force), Bangalore - 560007 , Karnataka, India. E-mail: inji63@gmail.com

Few useful webzines in Radiology and Imaging, which are available at the moment on the Internet are reviewed below:

1. Advance for Imaging and Radiation Oncology is a periodical available at http://imaging-radiationoncology.advanceweb.com/, which provides comprehensive, up-to-date news and information on management strategies, clinical/technological updates, and industry trends in medical imaging and radiation oncology. Sections on products, specialty, PACS/IT, education, and blogs are available.

2. Diagnostic Imaging Magazine at http://www. diagnosticimaging.com/home has many interesting sections like conference reports, insights on vendors, and product directory to name a few. A Topic index links to information on established modalities as well as emerging applications like colonography, digital X-ray, direct radiography, elastography, low-dose modalities, molecular imaging. In addition, there are sections covering newsletter sign-up, radiology education, and white papers. Other online specialty resources from UBM Medica are available by links.

3. Health Imaging at http://www.healthimaging.com/ index.php?option $=$ com_articlesanddivision $=$ hiit is a website focusing on images, information and knowledge across the enterprise. Sections that are available are top stories, newsletter, healthcare webcasts and whitepapers. The digital version of the magazine is available for viewing by a special link. Certain other

\begin{tabular}{|l|l|}
\hline \multicolumn{2}{|c|}{ Access this article online } \\
\hline Quick Response Code: & \\
\hline & Website: \\
\hline
\end{tabular}

features like web exclusives, latest news, most popular, mergers and acquisitions are also presented.

4. Imaging Economics at htp://www.imagingeconomics. $\mathrm{com} /$ is a journal that provides a monthly, highlevel forum to address the "development, diffusion, acquisition, and utilization of imaging technology". Interesting sections include white paper resources, regulatory watch, imaging informatics and expert insight. Moreover, the webzine Medical Imaging,

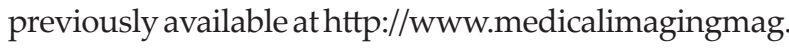
com/about.asp, is now amalgamated into the Imaging Economics website.

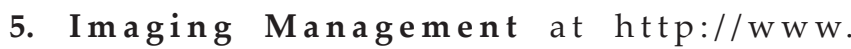
imagingmanagement.org/ focuses on the technology advances, methods to improve radiology services, best practice, better value-for-money investments, cost savings, imaging informatics and optimal patient and staff satisfaction. Sections on latest news, industry, research etc. are available. The archived issues are available at http://imagingmanagement.org/pdflibrary.

6. Imaging Technology News at http://www.itnonline.net/ is a technology solution resource for medical imaging and radiation oncology professional. Navigable sections lead initially to technology, articles, buyer's guide and comparison charts. Special featured websections have educative material on a range of topics like women's healthcare, imaging systems, information technology, advanced visualization, archive/storage, flat panel displays, radiation oncology, treatment planning software/systems, molecular imaging, fusion imaging software etc. The current issue is available at http:// www.itnonline.net/current_issue .

7. Medical Imaging International at http://www. medimaging.net/ is a journal focusing on the latest techniques in medical imaging. Sections cover clinical applications, scientific advances, new products, technical literature, and international events worldwide. 
Subjects covered include: radiology, ultrasound, MR imaging, nuclear medicine, radiotherapy, and industry news.

8. News-Line for Radiology Professionals at http://www. news-line.com/home.lasso?-token.profession=PX is an online magazine offering weekly e-mail newsletters, providing news and information relevant to radiology and imaging.

9. Radiology Today at http://www.radiologytoday.net/ is a monthly magazine that allows a professional to keep up with the fast-changing world of radiology. A broad range of topics include articles, archive, events, eNewsletter, and modalities like PACS/RIS/ Informatics. A Buyers Guide is on offer at http://www. radiologytoday.net/buyers_guide/2010/index.shtml, wherein nearly 40 radiology products/equipments can be researched. The current issue is available at http:// www.radiologytoday.net/current_issue.shtml.

10. RT image is a weekly online source for radiology professionals and available at http://www.rt-image. com/. The web portal offers separate sections on blogs, $\mathrm{CME} / \mathrm{CE}$, archives and a newsletter. The digital version of the magazine is on offer for viewing by a special link. A special section titled "datasheets" compares different machines and equipments of several vendors and on offer at http://www.rt-image.com/datasheets.cfm.

\section{Endpiece}

Philips Medical Systems has its online magazines Medica Mundi and Field Strength sourced at http://www. healthcare.philips.com/in_en/about/News/Publications/ index.wpd. Medica Mundi at http://www.healthcare.
philips.com/main/about/News/Publications/MedicaMundi/ index.wpd is a professional journal for users of Philips medical equipment and healthcare solutions. Its archive is retrievable from http://www.healthcare.philips.com/ in/about/news/publications/medicamundi/index.wpd. Similarly, Field Strength provides regular features and articles on MR Technologies and is on offer at http:// www.healthcare.philips.com/in/about/news/publications/ fieldstrength/index.wpd.

Siemens Somatom Sessions is an "educational program provided by Siemens Medical Solutions for state of the art CT scanning articles and case studies". The online version of Siemens CT magazine Somatom Sessions is accessible at http://www.siemens.com/entry/in/en/?tab=healthcare or alternatively from http://www.ctisus.com/somatom_ sessions/. Siemens Magnetom Flash is a magazine designed for physicians, physicists, and technical medical personnel from the world of MRI. Axiom Innovations is a magazine covering angiography, cardiology, fluoroscopy, and radiology. All three magazines can be located from the search field at http://www.siemens.com/entry/in/ en/?tab=healthcare.

Toshiba Insight at http://toshibainsight.com/ is a periodical from Toshiba that offers information catalogued into clinical cases, education and training, future technology, medical equipment and medical imaging. GE Healthcare Systems offers a radiology related blog at http://gehealthcare. typepad.com/ge_healthcare_blog/radiology/.

Healthcare Informatics at http://www.healthcareinformatics.com/ME2/Default.asp is a webportal dealing with healthcare IT leadership vision and strategy. The site covers the gamut of hospital operations with a special section on imaging. 